\title{
Engineering PD-1-Presenting Platelets for Cancer Immunotherapy
}

\author{
Xudong Zhang, ${ }^{\dagger, \ddagger, \S}$ Jinqiang Wang, ${ }^{\ddagger, \S}$ Zhaowei Chen, ${ }^{\S}$ Quanyin $\mathrm{Hu},{ }^{\S}$ Chao Wang, ${ }^{\S}$ Junjie Yan, ${ }^{\S}$

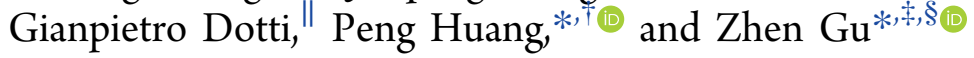

${ }^{\dagger}$ Guangdong Key Laboratory for Biomedical, Measurements and Ultrasound Imaging, Laboratory of Evolutionary Theranostics, School of Biomedical Engineering, Health Science Center, Shenzhen University, Shenzhen 518060, China

${ }^{\ddagger}$ Department of Bioengineering, California NanoSystems Institute, and Center for Minimally Invasive Therapeutics (C-MIT), University of California, Los Angeles, California 90095, United States

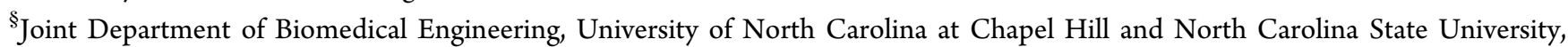
Raleigh, North Carolina 27695, United States

"Lineberger Comprehensive Cancer Center, University of North Carolina, Chapel Hill, North Carolina 27599, United States

\begin{abstract}
Radical surgery still represents the treatment choice for several malignancies. However, local and distant tumor relapses remain the major causes of treatment failure, indicating that a postsurgery consolidation treatment is necessary. Immunotherapy with checkpoint inhibitors has elicited impressive clinical responses in several types of human malignancies and may represent the ideal consolidation treatment after surgery. Here, we genetically engineered platelets from megakaryocyte (MK) progenitor cells to express the programmed cell death protein 1 (PD-1). The PD-1 platelet and its derived microparticle could accumulate within the tumor surgical wound and revert exhausted $\mathrm{CD} 8^{+} \mathrm{T}$ cells, leading to the eradication of residual tumor cells. Furthermore, when a low dose of cyclophosphamide

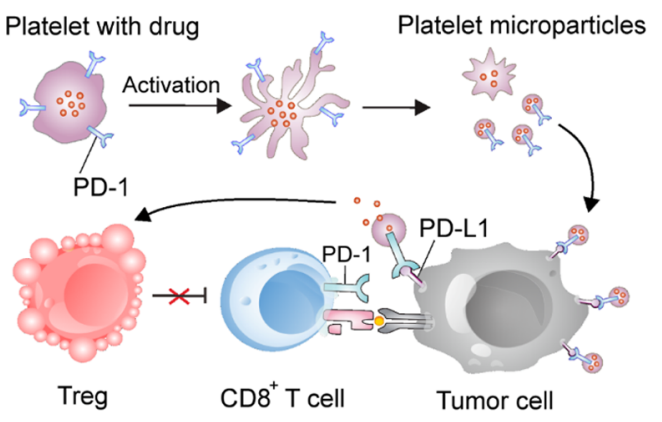
(CP) was loaded into PD-1-expressing platelets to deplete regulatory $\mathrm{T}$ cells (Tregs), an increased frequency of reinvigorated $\mathrm{CD}^{+}$lymphocyte cells was observed within the postsurgery tumor microenvironment, directly preventing tumor relapse.
\end{abstract}

KEYWORDS: Drug delivery, platelet, immune checkpoint blockade, immunotherapy, nanomedicine

S urgery is the main therapeutic option for most solid tumors. However, the local and distal tumor relapses frequently occur because of the incomplete resection of tumors. ${ }^{1,2}$ Hence, there have been tremendous interests in developing effective strategies to prevent cancer relapse after surgery. ${ }^{3,4}$ For example, tumor antigen-specific $\mathrm{CD}^{+} \mathrm{T}$ cells contribute to the eradication of residual tumor cells, ${ }^{5}$ especially those that harbor neoantigens (mutant protein-derived antigens). ${ }^{6-9}$ However, PD-L1 expression in tumors suppresses $\mathrm{T}$ cell responses by causing $\mathrm{T}$ cell exhaustion. ${ }^{10}$ Exhausted $\mathrm{T}$ cells are restrained by PD-L1 ligands through the inhibitory receptors PD-1 disabling the production of immune cytokines such as interferon- $\gamma$ (IFN- $\gamma$ ), tumor necrosis factor- $\alpha$ (TNF- $\alpha$ ), granzyme B, and perforin. ${ }^{11,12}$

Blocking the PD-1/PD-L1 axis by using checkpoint antibodies can reinvigorate exhausted $\mathrm{T}$ cells having led to the eradication of the tumor in $\sim 30 \%$ of the patients with melanoma and other types of cancers. ${ }^{13-15}$ However, more than half of patients are not responsive or only transiently responsive to $\mathrm{PD}-1 / \mathrm{PD}-\mathrm{L} 1$ blockade due to the existence of multiple immune evasion mechanisms. ${ }^{16}$ For instance, studies indicate that there are many intrinsic and extrinsic tumorassociated mechanisms of resistance to immunotherapy that include loss of targeted tumor-associated antigens, down- regulation of major histocompatibility complex (MHC) molecules, expression of other immune checkpoint receptors, and abundance of immune suppressive cell populations (Tregs, type II macrophages, myeloid-derived suppressor cells (MDSCs)). ${ }^{16}$ In particular, in addition to inhibiting effector $\mathrm{T}$ cells, Tregs compete in the consumption of interleukin-2 (IL-2) in the tumor microenvironment further impairing the proliferation of tumor infiltrated $\mathrm{CD}^{+} \mathrm{T}$ cells. ${ }^{17,18}$ Moreover, activated Tregs may also directly kill $\mathrm{T}$ cells through perforin. ${ }^{19}$ Thus, abundant Tregs in tumor tissue are crucial obstacles to achieve successful cancer immunotherapy. ${ }^{20}$ Depletion of Tregs can significantly improve the response rate of PD-1/ PD-L1 blockade. ${ }^{14}$

As the monitor of vascular damage, platelets can accumulate to the surgery wound. ${ }^{21,22}$ By employing this property, platelets conjugated with anti-PD-L1 can accumulate within the tumor surgery wound, reinvigorating exhausted $\mathrm{CD}^{+} \mathrm{T}$ cells, and thus reduce postsurgical tumor recurrence and metastasis. ${ }^{23}$ Moreover, platelet membrane is used to design formulations

Received: June 7, 2018

Revised: July 17, 2018

Published: July 31, 2018 


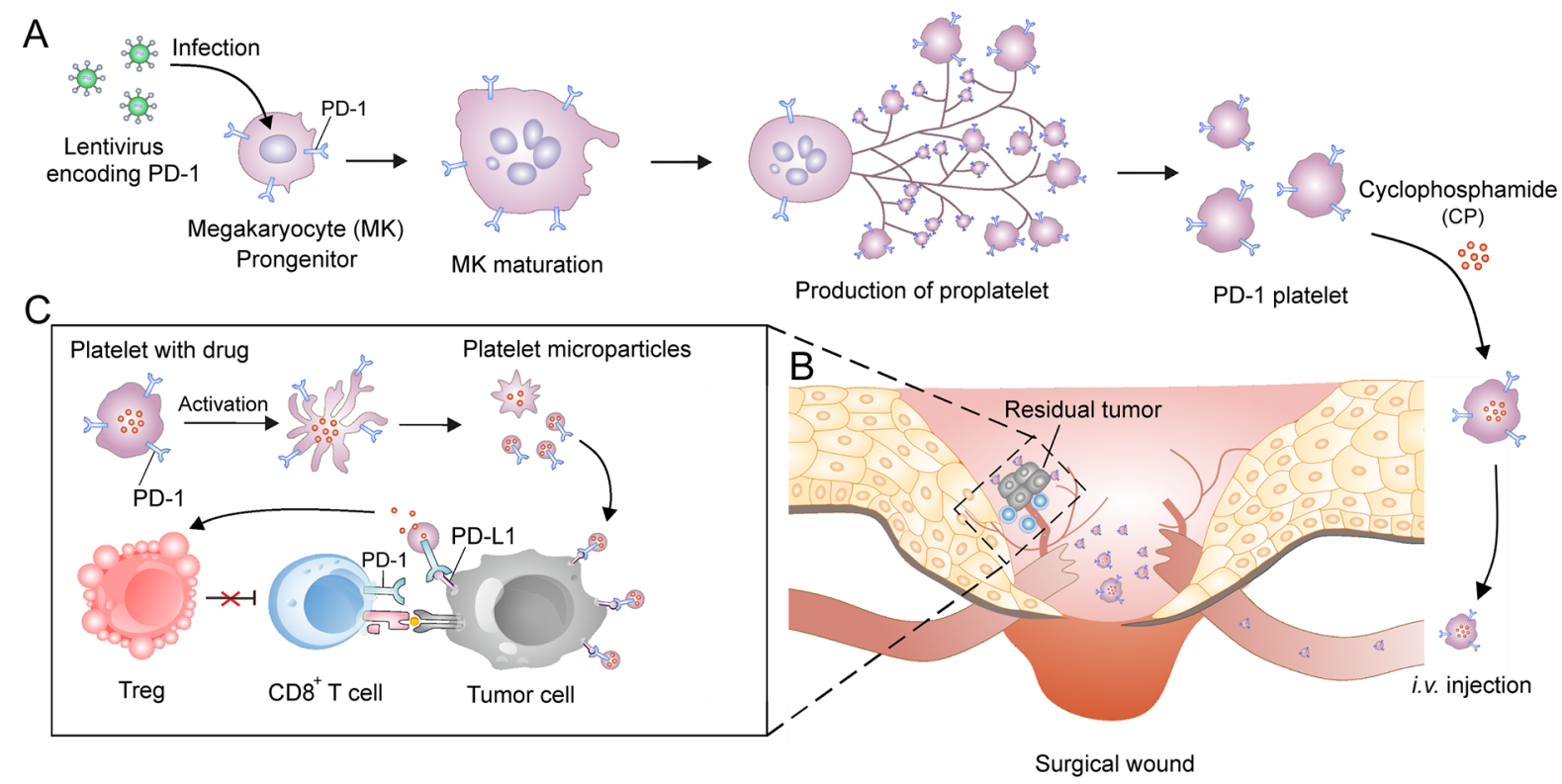

Figure 1. Schematic of the production of PD-1-expressing platelets and reinvigoration of $\mathrm{CD}^{+} \mathrm{T}$ cells. (A) Schematic shows L8057 cell line stably expressing murine PD-1 and production of platelets. (B) PD-1-expressing platelets target tumor cells within the surgery wound. (C) PD-L1 blockade by PD-1-expressing platelets reverts exhausted $\mathrm{CD}^{+} \mathrm{T}$ cells to attack tumor cells.

for wound and inflammation targeting cancer treatment. ${ }^{24-27}$ However, since blood-originated platelets are non-nucleated and terminally differentiated cells, they cannot be expanded $e x$ vivo and genetically manipulated to stably express transgenes, which significantly limit their clinical use as payload for cancer immunotherapy. ${ }^{28}$ In contrast, in vitro production of platelets from megakaryocytes (MKs) can provide a large source of platelets and be genetically modified. ${ }^{29,30}$ Herein, we genetically engineered murine MKs to stably express murine PD-1 and to produce mature platelets presenting PD-1 in vitro. We then applied these cells to target tumor cells within the surgical wound via reinvigoration of exhausted $\mathrm{CD}^{+} \mathrm{T}$ cells (Figure 1). In addition to PD-L1 blockade, PD-1-expressing platelets can also carry and transport cyclophosphamide, which allows the depletion of Tregs within the tumor microenvironment and further enhances the antitumor effects of $\mathrm{CD}^{+} \mathrm{T}$ lymphocyte cells within the surgical tumor microenvironment.

Platelets are released from the bone marrow and lung resident MKs. ${ }^{31}$ To produce platelets in large-scale, we treated the murine MK progenitor cells L8057 with phorbol 12myristate 13-acetate (PMA). After stimulation, cell volume was significantly increased, accompanied by proplatelet extension (Figure S1A,B) and platelets release (Figure S1C,D). MKs with larger cell volume containing polyploid nuclei were observed, indicating MK maturation and readiness for releasing the platelets (Figure S2). To generate PD-1-expressing platelets, L8057 cell line stably expressing murine EGFP-PD1 was established by infection with lentivirus and selection with puromycin (Figure S3). ${ }^{32}$ Remarkably, PD-1 was expressed and localized on the cell membrane, as indicated by the colocalization of fluorescence from EGFP and the cell membrane dye Alexa Fluor 594-conjugated wheat germ agglutinin (WGA594) (Figure 2A). PD-1 expression on EGFP-PD-1 L8057 cells was confirmed by Western blot (Figure 2B). CD41a, the marker of MKs, was intensively expressed on PD-1 L8057 cell line (Figure S4A). After the stimulation with PMA, PD-1-expressing L8057 cells underwent maturation, and morphologically displayed typical peripheral nuclei and increased cytoplasmic volume (Figure S4B). CD42a, a marker of MK maturation, was expressed on the cell membrane (Figure 2C). Moreover, the platelet surface receptors glycoprotein VI (GPVI) and P-selectin were expressed in mature PD-1 L8057 cells (Figure S4C,D). Wright-Giemsa staining revealed that mature PD-1 L8057 cells contained polyploid nuclei (Figure 2D).

Mature MKs typically reside in bone marrow and lung budding podosomes and prolong to form proplatelets. ${ }^{33}$ Proplatelets cross through the sinusoidal endothelium and release platelets into the bloodstream. ${ }^{31,33}$ Similarly, mature PD-1-expressing L8057 cells had budding podosomes, which prolonged to form the proplatelets (Figure $2 \mathrm{E}$ ). Notably, the proplatelets were budded and extended from the cell membranes to form pearl-like structures (Figure 2F). The proplatelets finally disbanded and released platelets (Figure S5A,B). MK cytoplasm containing EGFP-PD- $1^{+}$membrane vesicles existed as a membrane reservoir for proplatelet formation (Figure 2F). These PD-1-expressing membrane vesicles fused to form tubular structure and budded from the cell surface (Figure 2F). Purified platelets from the culture media showed green fluorescence indicating that PD-1 was present in the platelets (Figure 2G). Binding receptors including GPVI and P-selectin were also expressed in platelets released from L8057 cells (Figure S5C). Moreover, dynamic light scattering (DLS) analysis showed that the average diameter of the platelets was around $1.5 \mu \mathrm{m}$ and with a $\zeta$ potential of $-10 \pm 2.6 \mathrm{mV}$ (Figure $2 \mathrm{H}$ and Figure S5D). As documented by cryo-scanning electron microscopy (CSEM) and transmission electron microscopy (TEM), purified platelets showed spherical morphology (Figure 2I,J). We further quantitatively measured the platelet production from PD-1-expressing L8057 cells and found optimal platelet production at day 6 after stimulation with PMA (Figure 2K).

Platelets execute hemostasis, recruit other leukocytes for host defense responses, and release several immunoreactive molecules after adhering to vascular lesions. ${ }^{34}$ Collagen is the primary subendothelial component for active platelet binding. 
A
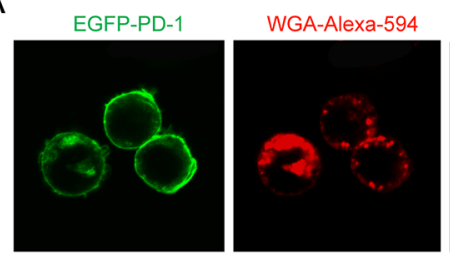

C

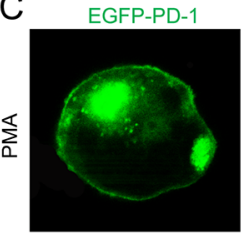

E EGFP-PD-1/DAPI
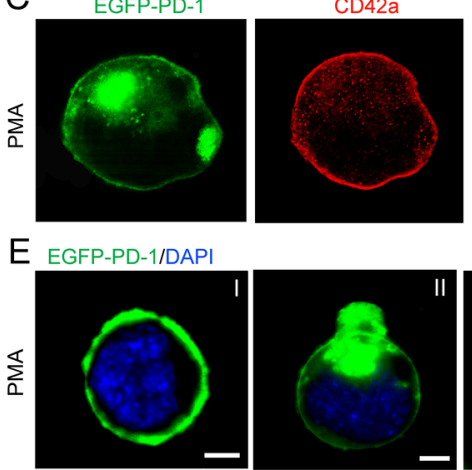

Overlay/DAP|

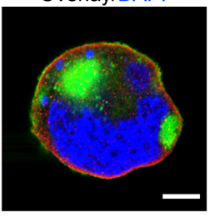

B

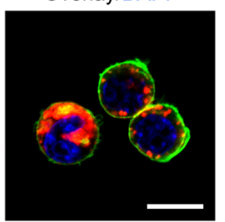

$\mathrm{D}$
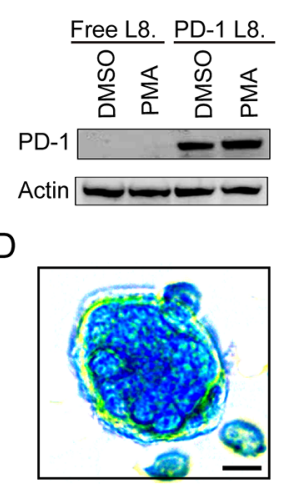

G
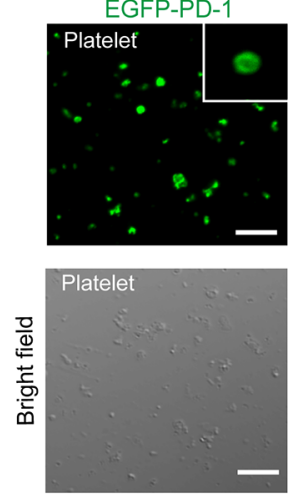

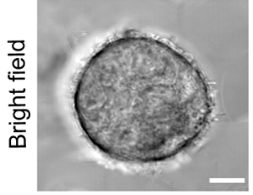

$\mathrm{F}$
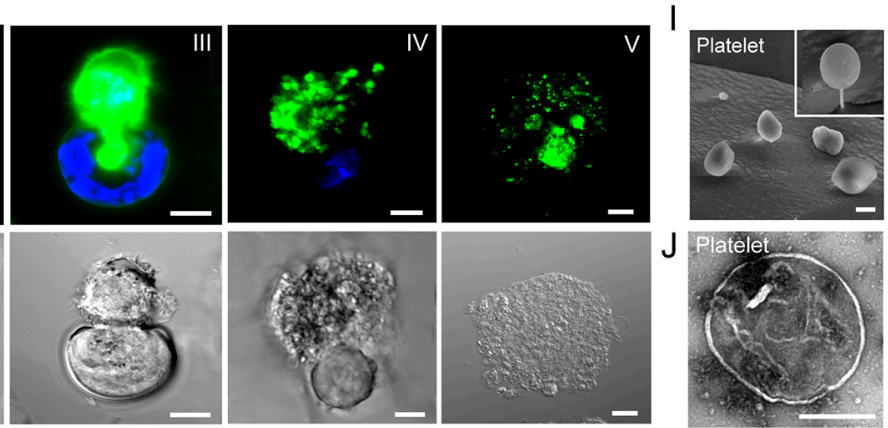

$\mathrm{H}$

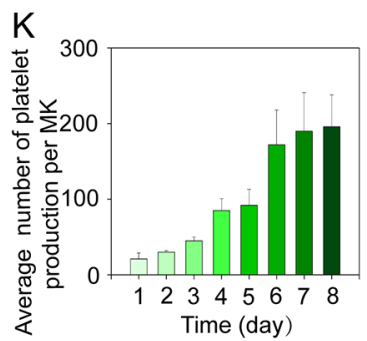

Figure 2. Production and characterization of platelets from PD-1-expressing L8057 stable cell line. (A) Confocal images present L8057 cell line stably expressing murine EGFP-PD-1 on cell membranes. WGA Alexa-Fluor 594 dye was used to stain cell membrane (scale bar: $10 \mu \mathrm{m})$. (B) Western blot analysis for evaluating the expression of PD-1 in L8057 cell line. L8 is short for L8057 cells. (C) EGFP-PD-1-expressing L8057 cells stimulated with $500 \mathrm{nM}$ PMA for 3 days, and immunostained to detect CD42a expression. (D) L8057 cells stimulated with $500 \mathrm{nM}$ PMA for 3 days, and stained with Wright-Giemsa dye (scale bar: $10 \mu \mathrm{m}$ ). (E) Evolution process of PD-1-expressing proplatelet extended from MKs (scale bar: $10 \mu \mathrm{m}$ ). (F) Morphology of PD-1 proplatelets extended from L8057 cells after 6 days of stimulation with $500 \mathrm{nM}$ PMA. PD-1 proplatelets extended from L8057 cells (scale bar: $10 \mu \mathrm{m}$ ). (G) Representative confocal images of purified PD-1-expressing platelets (scale bar: $10 \mu \mathrm{m})$. (H) Size distribution of PD-1-expressing platelets measured by DLS. (I) CSEM image shows the morphology of PD-1-expressing platelets (scale bar: 1 $\mu \mathrm{m})$. (J) Representative TEM image shows morphology and size of PD-1-expressing platelet (scale bar: $1 \mu \mathrm{m})$. (K) Number of platelets released from PD-1-expressing L8057 cells after stimulated with $500 \mathrm{nM}$ PMA $(n=5)$. Error bar, \pm SD.

As illustrated in Figure 3A,B, WGA Alexa-Fluor 594 dyelabeled free and PD-1-expressing platelets showed similar collagen adhesion ability. In contrast, blockade of the collagen receptor GPVI reduced the collagen adhesion ability of the platelets (Figure S6A). Thrombus formation by platelet aggregation is another critical event of the hemostatic response. $^{35}$ Free and PD-1-expressing platelets efficiently aggregated in response to agonistic stimulation with thrombin (Figure S6B). Platelet microparticles (PMPs) are generated from activated platelets. ${ }^{36,37}$ To examine whether PMPs are generated from activated PD-1-expressing platelets upon stimulation, we treated the platelets with thrombin in vitro. Confocal laser scanning microscopy (CLSM), SEM, and TEM images indicated the generation of PMPs from activated platelets (Figure 3C and Figure S6C). Platelets became more dendritic and expansive after the treatment with thrombin (Figure 3C). Furthermore, DLS analysis detected the generation of small particles, substantiating the release of PMPs from activated platelets (Figure 3D).

Elevation of PD-L1 expression in tumor cells causes exhaustion of $\mathrm{T}$ cells expressing $\mathrm{PD}-1 .^{10}$ To investigate whether PD-1 expressed platelets could bind to the surface of the melanoma cells and block PD-L1, we incubated the PD1-expressing platelets with the B16F10 melanoma cells in vitro. We observed that PD-1-expressing platelets bound to B16F10 cells and were then internalized by the cancer cells (Figure $3 \mathrm{E}$ and Figure S7). In contrast, free platelets showed limited ability to bind to the B16F10 cells (Figure 3E). To examine whether the PD-L1/PD-1 interaction mediated the internalization of platelets, we added anti-PD-L1 antibody to block PD-L1 on the B16F10 cells. The confocal images showed that PD-1 platelets binding was significantly reduced when PD-L1 antibody was preincubated with the cells (Figure S7A). Furthermore, the EGFP-PD-1-expressing platelets colocalized 

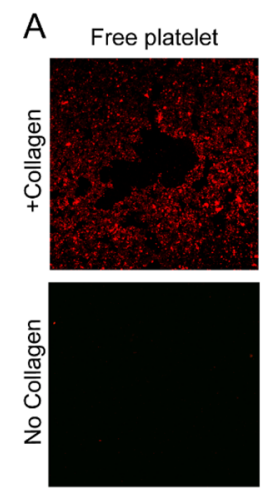

C
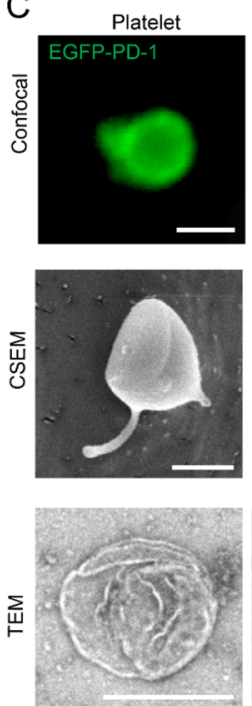

G
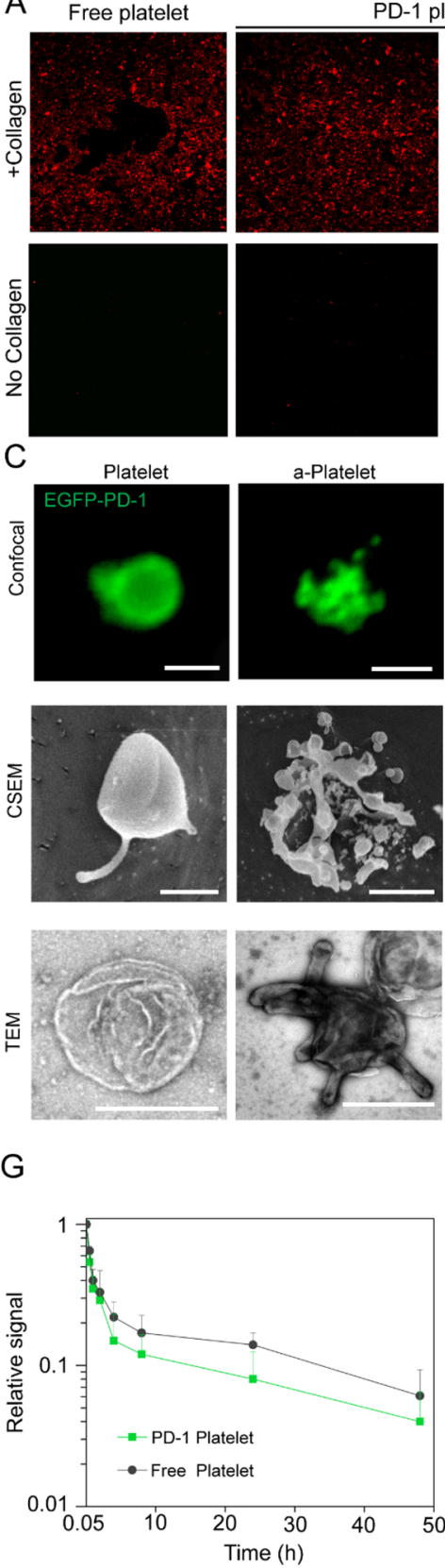

a-Platelet
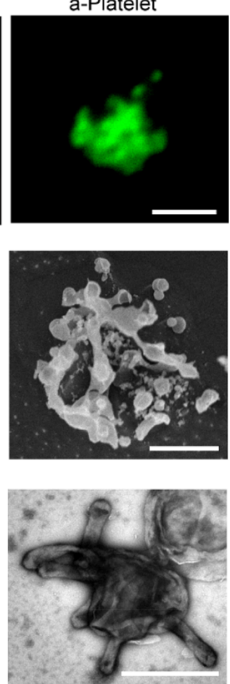

B
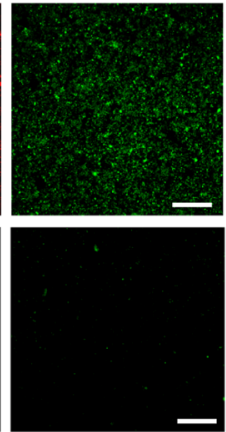

PMPS
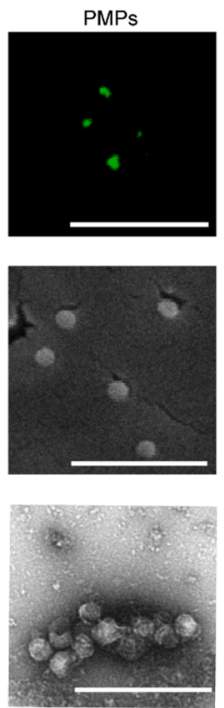

$\mathrm{H}$
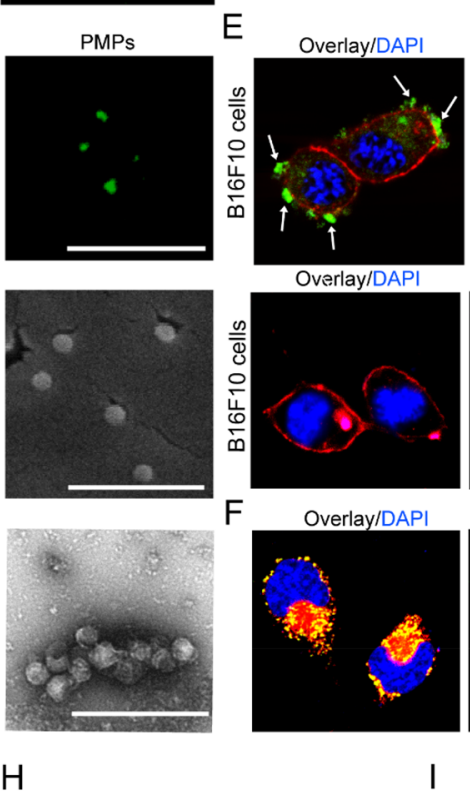
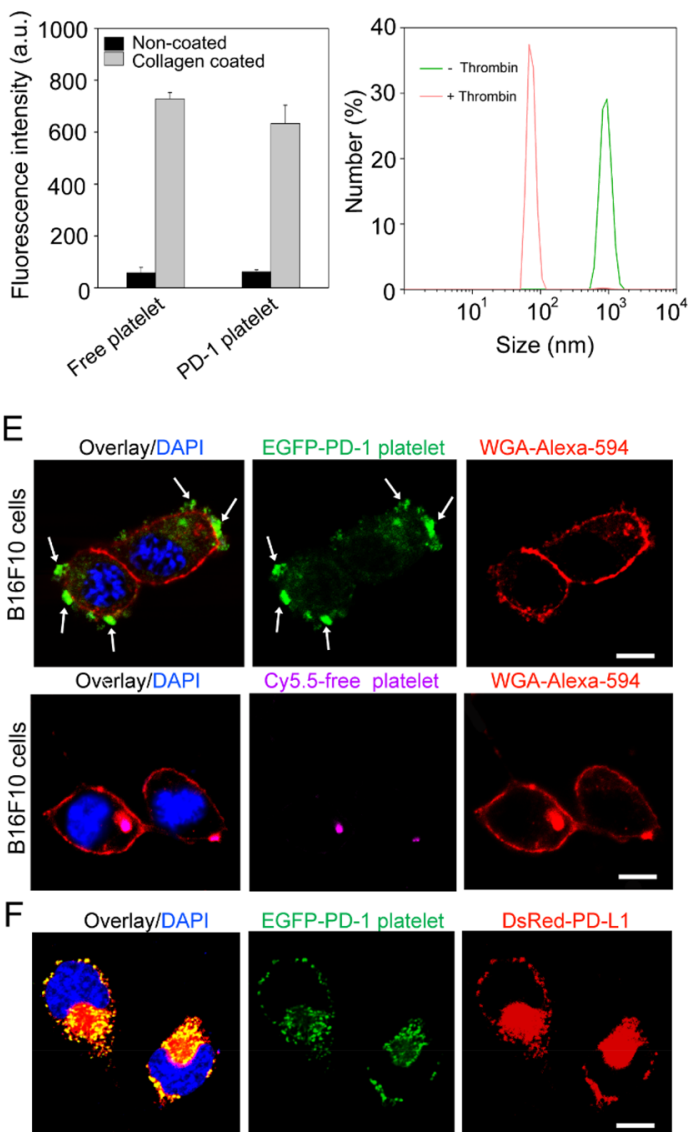

DsRed-PD-L1
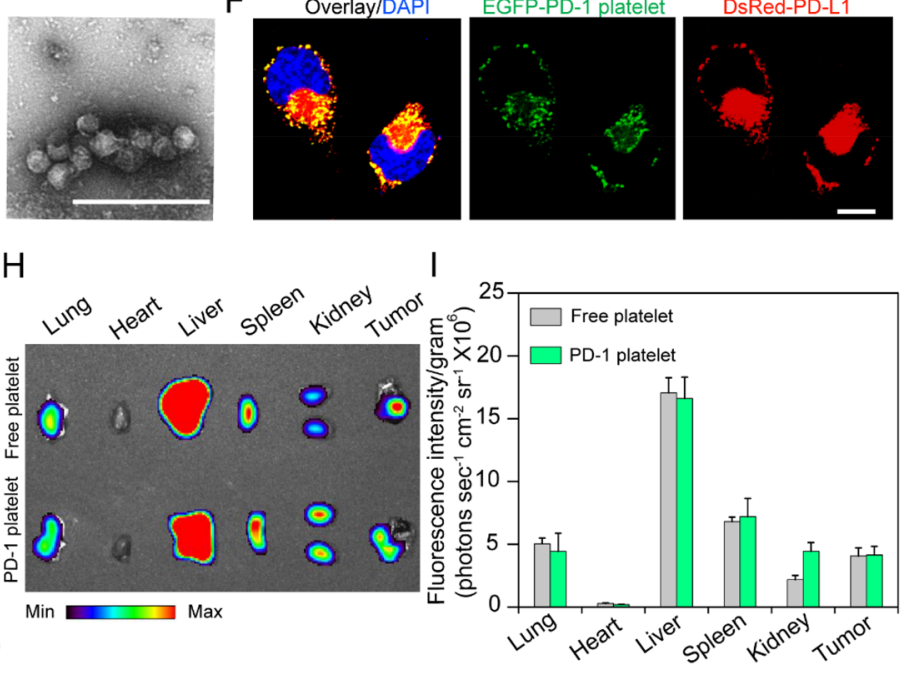

Figure 3. In vitro and in vivo function of PD-1-expressing platelets. (A, B) Retention of platelets on collagen-coated or uncoated tissue culture slides. Green color: EGFP; Red color: WGA Alexa-Fluor 594 dye (scale bar: $50 \mu \mathrm{m}$ ). Error bar, \pm SD. (C) Confocal, CSEM, and TEM images of PD-1-expressing platelets stimulated with thrombin. Platelet microparticles (PMPs) were released from the platelet (scale bar: $1 \mu \mathrm{m}$ ). (D) Measurement of the size distribution of PD-1-expressing platelets at $30 \mathrm{~min}$ after activation by thrombin. PMPs were produced from the platelets. (E) EGFP-PD-1-expressing platelets bound on the cell membrane of B16F10 cells. PD-1-expresing platelets or free platelets labeled with Cy5.5 were incubated with B16F10 cells for $20 \mathrm{~h}$. WGA Alexa-Fluor 594 dye was used to stain the B16F10 cell membrane. The white arrows indicate the PD-1 platelets binding on the cell membrane of the cancer cells (scale bar: $10 \mu \mathrm{m}$ ). (F) B16F10 cells were transfected with DsRed-PD-L1 plasmid for $20 \mathrm{~h}$, and then incubated with EGFP-PD-1 platelets for $20 \mathrm{~h}$; the colocalization of EGFP-PD-1 platelets and DsRed-PD-L1 was detected (scale bar: $10 \mu \mathrm{m}$ ). (G) Cy5.5-labeled free platelets and PD-1-expressing platelets were injected through the tail-vein in mice. Fluorescence was measured at different time points $(n=3)$. Fluorescence intensity at $2 \mathrm{~min}$ as 1 . Error bar, $\pm \mathrm{SD}$. (H) In vivo fluorescence images of free platelets and PD-1expressing platelets in major organs and residual tumor bed. (I) Fluorescence intensity per gram of tissue in major organs and tumors $(n=3)$. Error bar, \pm SD

with DsRed-PD-L1 expressed by B16F10 melanoma cells, indicating the physical interaction between PD-1 and PD-L1 (Figure 3F). To investigate the in vivo biodistribution of free and PD-1-expressing platelets, Cy5.5-labeled platelets were inoculated in mice via tail-vein injection. Free platelets showed longer blood retention than PD-1-expressing platelets (14\% vs
$8 \%$ at 24 h) (Figure 3G). When Cy5.5-labeled platelets were inoculated intravenously after tumor resection in B16F10 tumor-bearing mice, both free and PD-1 platelets could accumulate in the residual tumor bed (Figure 3H,I). Meanwhile the platelets intensively accumulated in the liver and spleen (Figure 3H,I). GPVI is the collagen receptor on the platelets 
A
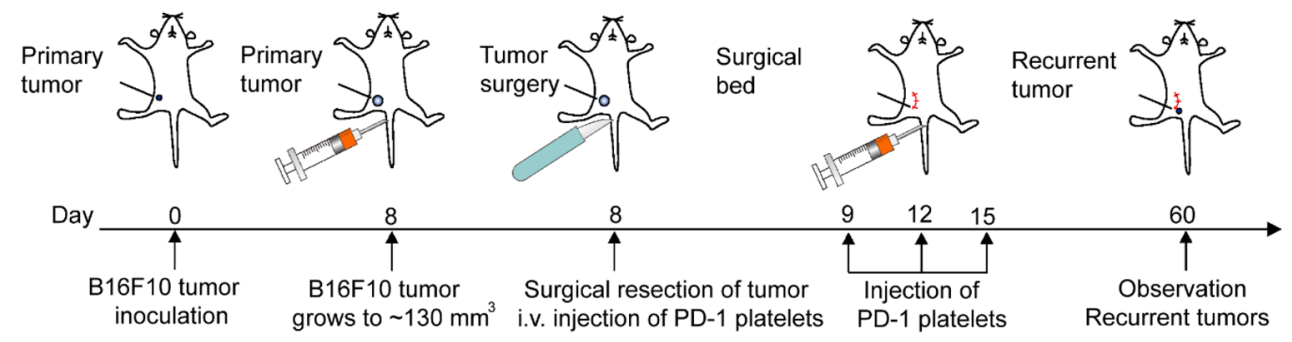

B

PBS (G1) free platelet (G2) PD-1 platelet (G3)
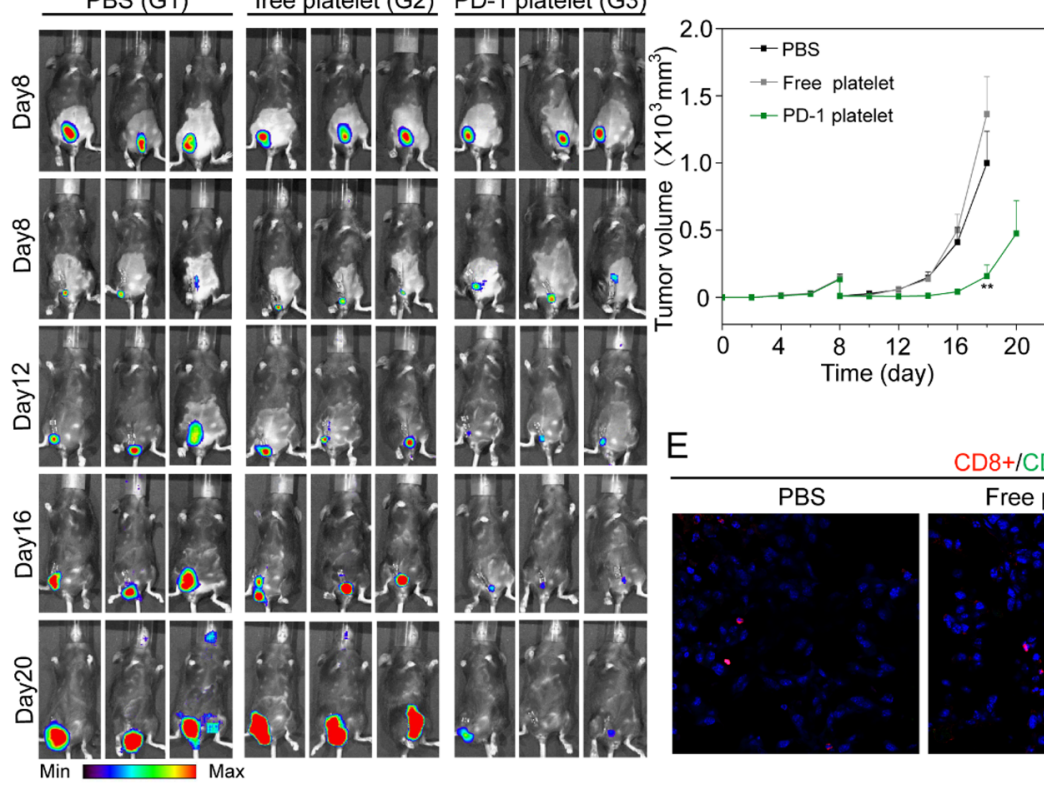

$\mathrm{D}$

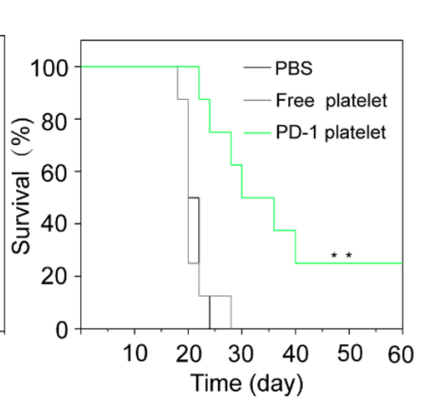

$\mathrm{E}$

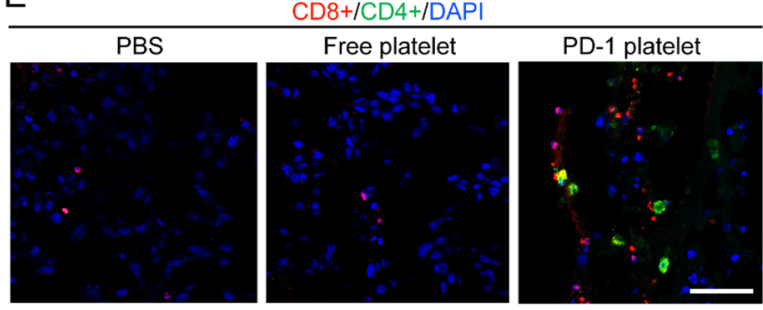

$\mathrm{F}$

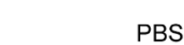

Free platelet

G
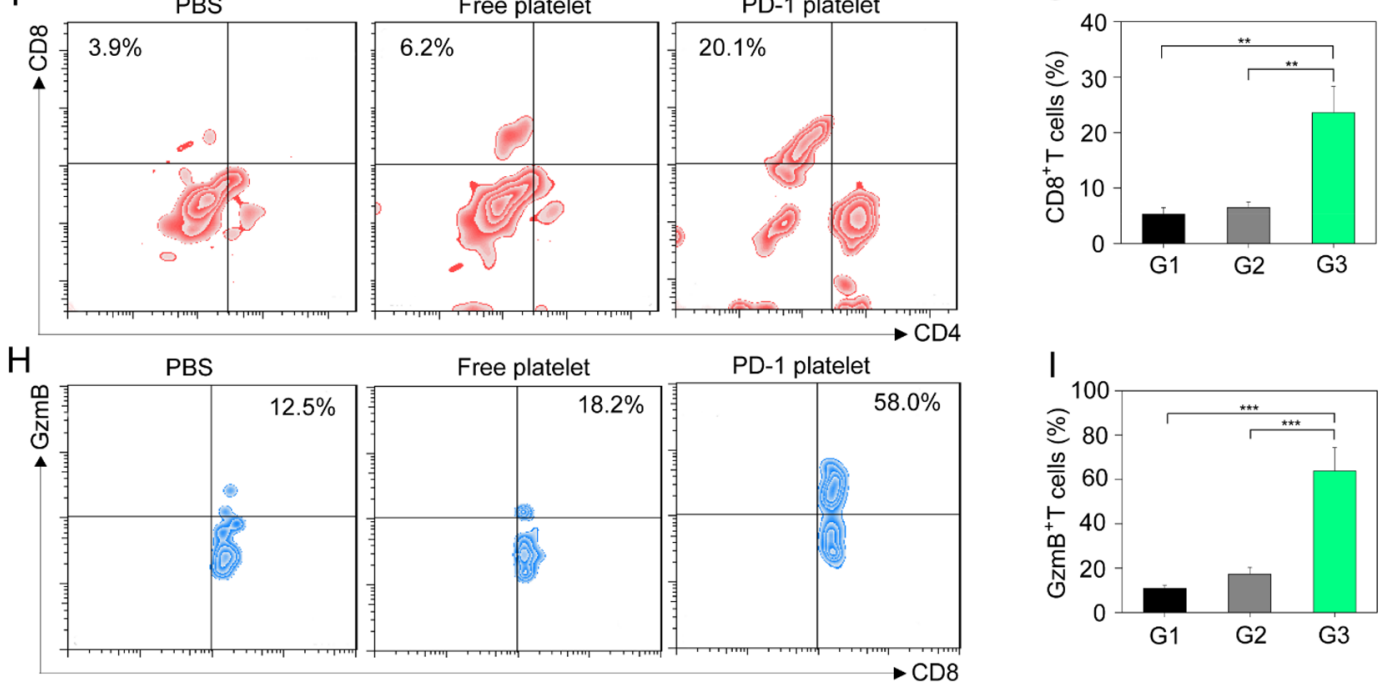

Figure 4. PD-1-expressing platelets for inhibition of tumor progression in incomplete-surgery tumor model. (A) Schematic illustration of PD-1expressing platelets used for therapy in an incomplete-surgery tumor model. (B) In vivo bioluminescence imaging of the B16F10 tumor growth in mice treated with PBS (G1), free platelets (G2), and PD-1-expressing platelets (G3). (C) Average tumor volumes of treated mice $(n=8)$. Data are shown as the mean \pm SEM. (D) Survival curves of mice receiving different treatments $(n=8)$. (E) Immunofluorescence of tumor sections showing infiltration of $\mathrm{CD}^{+}$and $\mathrm{CD}^{+} \mathrm{T}$ cells (scale bar: $100 \mu \mathrm{m}$ ). (F)Representative plots and (G) quantification of $\mathrm{T}$ cells in tumors analyzed by flow cytometry (gated on $\mathrm{CD}^{+} \mathrm{T}$ cells) $(n=3)$. Error bar, $\pm \mathrm{SD}$. $(\mathrm{H})$ Representative plots and (I) quantification of GzmB in CD8 ${ }^{+} \mathrm{T}$ cells in tumors analyzed by the flow cytometry (gated on $\mathrm{CD} 8^{+} \mathrm{T}$ cells) $(n=3)$. Error bar, $\pm \mathrm{SD}$. Throughout, NS, not significant; $* P<0.05$; $* * P<0.01 ; * * * P<$ 0.001. (C, G, I) One-way ANOVA with Tukey posthoc test analyses were carried out to do the analyses, or (D) by log-rank (Mantel-Cox) test.

and is responsible for the platelets targeting the wound. PD-1 platelets and free platelets showed similar binding ability on the collagen (Figure 3A). Therefore, the accumulation ability in the surgical tumors is similar between the free platelets and PD-1 platelets (Figure 3H).
To investigate whether PD-1-expressing platelets prevent cancer relapse after surgery, we utilized the B16F10 melanoma incomplete-tumor-resection model to mimic the postsurgical local relapse (Figure 4A). Tumor-bearing mice were injected intravenously with phosphate-buffered saline (PBS), free 
A

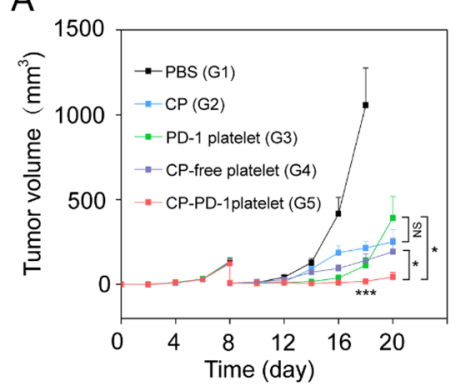

D

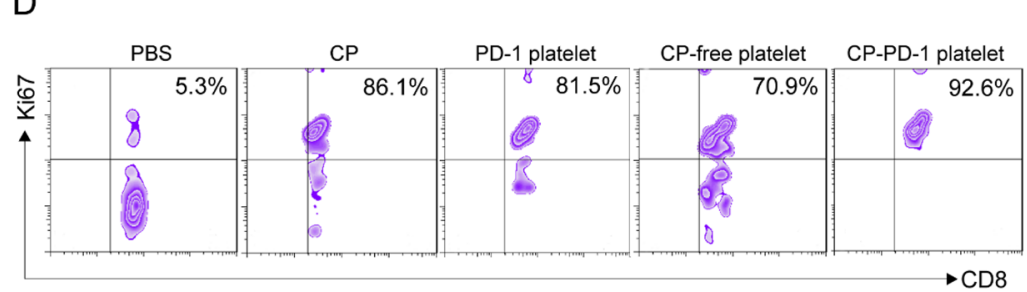

F

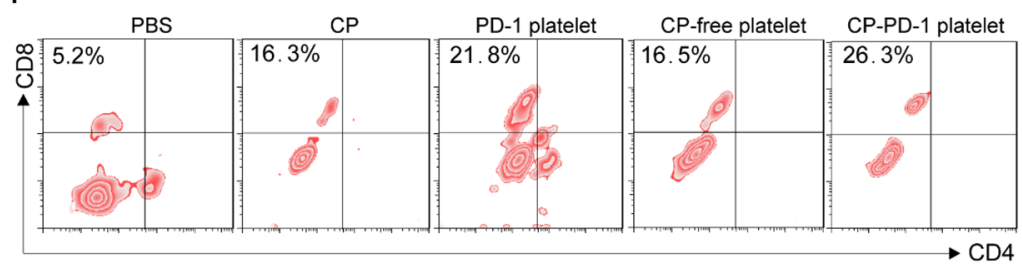

$\mathrm{H}$

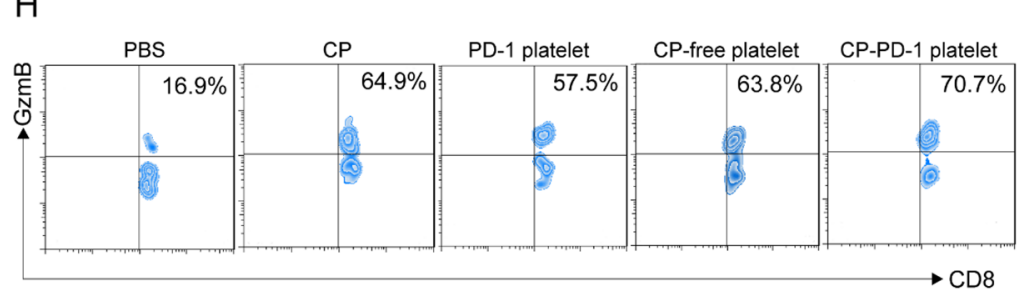

$\mathrm{J}$

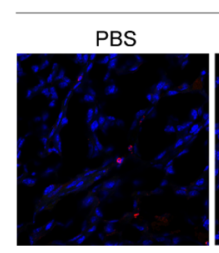

B

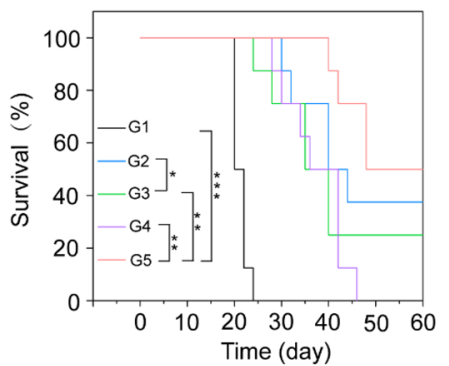

C

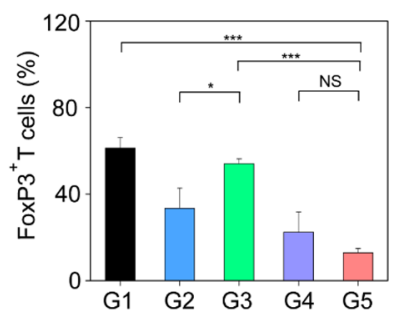

E

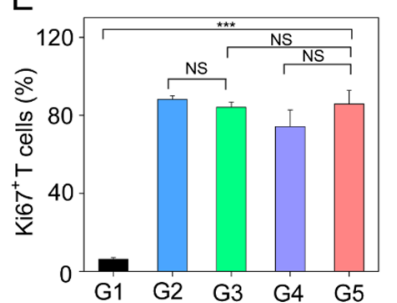

G

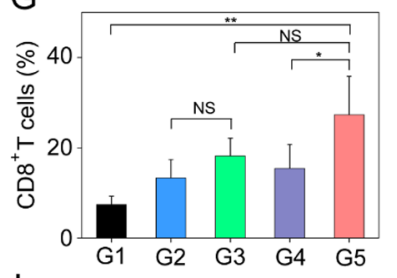

I

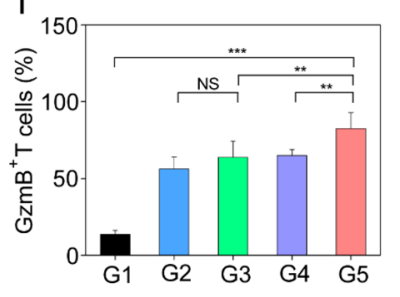

$\mathrm{K}$

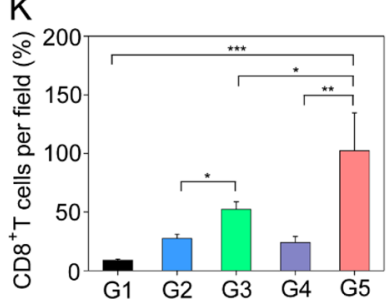

Figure 5. In vivo antitumor effect of cyclophosphamide-loaded PD-1-expressing platelets in incomplete-surgery tumor model. (A) Average tumor volumes of mice $(n=8)$ treated with PBS (G1), cyclophosphamide (CP) (G2), PD-1-expressing platelets (G3), CP-free platelets (G4), and CPloaded PD-1-expressing platelets (G5). Data are shown as the mean \pm SEM. ***, Compared with PBS control. (B) Survival curves of the treated mice. (C) Quantification of FoxP3 expression in $\mathrm{CD}^{+} \mathrm{T}$ cells within the tumors analyzed by the flow cytometry (gated on $\mathrm{CD} 4^{+} \mathrm{T}$ cells) $(n=3)$. (D) Representative plots and (E) quantification of Ki67 in $\mathrm{CD}^{+} \mathrm{T}$ cells within the tumors analyzed by the flow cytometry (gated on CD8 ${ }^{+} \mathrm{T}$ cells) $(n=3)$. (F) Representative plots and $(\mathrm{G})$ quantification of $\mathrm{CD} 8^{+}$and $\mathrm{CD} 4^{+} \mathrm{T}$ cells within tumors analyzed by the flow cytometry (gated on $\mathrm{CD} 3^{+}$ $\mathrm{T}$ cells) $(n=3)$. (H) Representative plots and (I) quantification of GzmB in $\mathrm{CD}^{+} \mathrm{T}$ cells within the tumors analyzed by the flow cytometry (gated on $\mathrm{CD}^{+} \mathrm{T}$ cells) $(n=3)$. (J, K) Immunofluorescence of the tumors showing CD8 ${ }^{+} \mathrm{T}$ cell infiltration (scale bar: $\left.100 \mu \mathrm{m}\right)$. Error bar of C, E, G, I, $\mathrm{K}, \pm \mathrm{SD}$. Throughout, NS, not significant; $* P<0.05 ; * * P<0.01 ; * * P<0.001$. (A, C, E, G, I, K) Two-way ANOVA with Tukey posthoc test analyses were carried out to do the analyses or (B) by log-rank (Mantel-Cox) test (B).

platelets $\left(2 \times 10^{8}\right)$, or PD-1-expressing platelets $\left(2 \times 10^{8}\right)$. After platelet infusion, tumors were resected to remove $~ 90 \%$ of the tumor mass. After surgery, mice received additional treatment during the period of wound healing (Figure 4A). We observed tumor growth delay in mice treated with PD-1expressing platelets as assessed by monitoring the tumor bioluminescence and measuring the tumor size (Figure 4B,C, and Figure S8A). In contrast, tumors rapidly progressed in mice that received free platelets or PBS (Figure 4B,C, and Figure S8A). There were $25 \%$ of mice receiving PD-1expressing platelets that survived more than 60 days without obvious weight loss or other signs of toxicities (Figure 4D and Figure S8B). The major organs such as liver, spleen, kidney, heart, and lung were collected and assessed by immunohistochemistry to assess the systemic toxicity. There was no obvious sign of organ damage observed in the platelets treated 
mice (Figure S9). Remarkably, we observed increased frequency of $\mathrm{CD}^{+}$TILs in the tumor of mice treated with PD-1-expressing platelets (Figure 4E-G), and $T$ cells exhibited increased expression of cytotoxic protein granzyme $\mathrm{B}(\mathrm{GzmB})$, indicating that PD-1-expressing platelets can revert $\mathrm{T}$ cell exhaustion within the tumor microenvironment (Figure $4 \mathrm{H}, \mathrm{I})$.

Low doses of cyclophosphamides can improve immune responses in various murine tumor models and patients, which is generally attributed to selective depletion of Tregs. ${ }^{38-40}$ To counter Tregs at the tumor site, we loaded the cyclophosphamide into the platelets. We found that platelets could internalize and release cyclophosphamide within $24 \mathrm{~h}$ in vitro (Figure S10). To investigate the simultaneous antitumor effect of PD-L1 blockade and cyclophosphamide-induced depletion of Tregs, we used the same B16F10 melanoma model with incomplete-tumor-resection. In this model, while cyclophosphamide and PD-1-expressing platelets showed limited results when used as single agents (Figure 5A and Figure S11A), tumor progression was significantly suppressed in mice treated with cyclophosphamide-loaded PD-1-expressing platelets $(P<0.001)$ (Figure $5 \mathrm{~A}$ and Figure S11A). Treg depletion by cyclophosphamide and PD-L1 simultaneously blockade by PD-1 improved the survival of the treated mice (Figure 5B).

We further investigated the frequencies of the $\mathrm{CD} 4^{+}$Tregs and $\mathrm{CD}^{+}$TILs in the tumor upon treatment. Free cyclophosphamide and cyclophosphamide-loaded platelets selectively depleted Tregs within the tumor (Figure 5C and Figure S11B) and increased the frequency of $\mathrm{Ki} 67^{+} \mathrm{T}$ cells (Figure 5D,E). Of note, despite PD-1-expressing platelets having limited effect in reducing Tregs, they still increased the frequency of $\mathrm{Ki}^{+} \mathrm{T}$ cells (Figure 5D,E). Remarkably, the frequency of $\mathrm{CD}^{+}$TILs was significantly increased in tumors collected from mice treated with cyclophosphamide-loaded PD-1-expressing platelets (Figure 5F,G), and these cells showed GzmB expression (Figure 5H,I). Immunofluorescence staining also revealed enhanced density of infiltrated $\mathrm{CD}^{+} \mathrm{T}$ cells in the mice treated with cyclophosphamide-loaded PD-1expressing platelets as compared to control mice (Figure 5J,K). Mice treated with a low dose of cyclophosphamide, and cyclophosphamide-loaded platelets showed delayed hair growth in the abdomen and slighted weight loss (Figure S11A,C). These results demonstrated that the combined utilization of PD-1-expressing platelets and cyclophosphamide effectively disrupted the immune blockade of PD-L1 and depleted the Tregs, leading to the reduced tumor relapse rate after surgery.

In summary, we generated a cellular drug delivery system that leverages PD-1-presenting platelets for enhanced cancer immunotherapy after surgery. The PD-1-expressing platelets could accumulate in the surgical wound sites upon intravenous infusion, block PD-L1 on residual tumor cells, and revert exhausted $\mathrm{CD}^{+} \mathrm{T}$ cells to eradicate residual tumor cells. Such platelets could also function as a carrier of drugs, such as cyclophosphamide, to simultaneously disrupt the immune suppressive effects of $\mathrm{PD}-\mathrm{L} 1$ and deplete Tregs, and promote the emergence of $\mathrm{CD}^{+} \mathrm{Ki} 67^{+} \mathrm{GzmB}^{+}$lymphocytes in the surgical tumor microenvironment. This cell-mediated delivery strategy can be further exploited to deliver other checkpoint blockade inhibitors toward the tumor site as well as other immunomodulatory drugs. ${ }^{41,42}$
Chemicals and Reagents. Cyclophosphamide, thrombin, Wright-Giemsa solution, and phosphatase inhibitor cocktail were from Sigma-Aldrich. Murine PD-1 and PD-L1 antibodies were from Thermo Scientific and Sigma-Aldrich, respectively. Murine CD41a (ab63983), CD42a (ab173503), CD4, and CD8 antibodies were from Abcam. P-Selectin (sc-8419) was from Santa Cruz biotechnology. Murine GPVI (MAB6758) antibody was from R\&D Systems. CD3, CD4, CD8, Ki67, and Foxp3 antibodies for FACS analysis were from Biolegend Inc. Wheat germ agglutinin (WGA) Alexa Fluor 488 and 594 dyes were from Thermo Scientific.

Cell Culture. HEK293T were cultured in Dulbecco's modified Eagle's medium (DMEM) supplemented with 10\% fetal bovine serum (FBS). Mouse megakaryocyte cell line L8057 was kindly provided by professor Alan Cantor (Boston Children's Hospital, Dana-Farber Cancer Institute) and was cultured in RPMI 1640 with 20\% FBS. The murine melanoma cell line B16F10 was obtained from the American Type Culture Collection. For bioluminescent in vivo tumor imaging, B16F10-luc cells were kindly provided by Dr. Leaf Huang at UNC. B16F10 cells were cultured in DMEM supplemented with $10 \%$ FBS.

Plasmid and Stable Cell Line. Lentivirus vector encoding murine PD-1 fused at C-terminal region with GFP-tag (pLentiC-mGFP-PD-1-puro) and Lenti-vpak packaging kit and transfection reagent were obtained from Origene. Mouse DsRed-PD-L1 plasmid was obtained from Sino biological. L8057 cells were infected with the lentivirus and incubated with $6 \mu \mathrm{g} / \mathrm{mL}$ polybrene. After infection, L8057 cells were cultured in RPMI 1640 with $20 \%$ FBS and with $1 \mu \mathrm{g} / \mathrm{mL}$ puromycin to select cell lines stably expressing murine PD-1. Established EGFP-PD-1 L8057 cells were maintained in 20\% FBS complementary with $0.5-1 \mu \mathrm{g} / \mathrm{mL}$ puromycin.

Preparation of Platelets from L8057 Cells. L8057 cells and PD-1-expressing L8057 cells were cultured in RPMI 1640 with $20 \%$ FBS. For maturation and differentiation, L8057 cells were stimulated with 100-500 nM PMA for 3 days. Cells were then cultured for another 6 days to produce proplatelets and platelets. To isolate platelets, the culture medium was centrifuged at $1500 \mathrm{rpm}$ for $20 \mathrm{~min}$ to remove the cells. Supernatant was then centrifuged at $12000 \mathrm{rpm}$ for $20 \mathrm{~min}$ at room temperature. Platelet precipitate was resuspended in Tyrode's buffer $(134 \mathrm{mM} \mathrm{NaCl}, 12 \mathrm{mM} \mathrm{NaHCO} 3,2.9 \mathrm{mM}$ $\mathrm{KCl}, 0.34 \mathrm{mM} \mathrm{Na}_{2} \mathrm{HPO}_{4}, 1 \mathrm{mM} \mathrm{MgCl}, 10 \mathrm{mM}$ HEPES, pH 7.4) or PBS with $1 \mu \mathrm{M}$ PGE1. To active platelets, $0.5 \mathrm{U}$ thrombin $/ \mathrm{mL}$ was added to the platelet suspension. PGE1 was removed prior to platelet activation.

Wright-Giemsa Stain. L8057 cells stimulated with 100500 nM PMA for 3 days were harvested and washed with PBS buffer. Cells were then fixed in absolute methanol for $5 \mathrm{~min}$, stained in Wright-Giemsa stain solution for $5 \mathrm{~min}$, washed with PBS buffer, and observed under microscope with $40 \times$ objective.

Cell Immunofluorescent Assay. EGFP-PD-1-expressing L8057 cells were washed with PBS and fixed with 4\% paraformaldehyde for $10 \mathrm{~min}$. Then the cells were washed with PBS, incubated with $0.2 \%$ Triton X-100 for 5 min, and blocked with the buffer containing 3\% BSA for $1 \mathrm{~h}$. After that, cells were stained with CD41a, CD42a, and P-selectin antibodies overnight at $4{ }^{\circ} \mathrm{C}$. After washing with PBS, cells were stained with Rhodamine-conjugated secondary antibody (KPL) diluted at room temperature and kept in the dark for $1 \mathrm{~h}$. The nucleus was stained with DAPI for $10 \mathrm{~min}$. After washing 
with PBS, confocal microscopy was performed on a FLUOVIEW laser scanning confocal microscope (Zeiss) in sequential scanning mode using a $63 \times$ objective.

Western Blot. Immunoblotting analysis was performed as previously described. ${ }^{43}$ L8057 control cells and L8057 cells stably expressing EGFP-PD1 were lysed with RIPA lysis buffer (Thermo Scientific), and cell lysates resolved on 12\% SDSPAGE. Immunoblotting was incubated with PD-1, CD41a, CD42a, P-selectin, GPVI, and $\beta$-actin antibodies, followed by enhanced chemiluminescence (ECL) detection (Thermo Scientific).

B16F10 Cell Binding Assay. B16F10 cells were seeded in confocal wells. EGFP-PD-1-expressing platelets and free platelets $\left(\sim 0.5 \times 10^{8}\right.$ cell/well $)$ labeled with cy5.5 were added to the culture medium and incubated with the B16F10 cells overnight. Wheat germ agglutinin (WGA) and Alexa Fluor 594 conjugate were added to stain the cell membrane of B16F10 for 10 min. The nucleus was stained with DAPI for 10 min. After washing with PBS, confocal microscopy was performed on a confocal microscope (Zeiss) in sequential scanning mode using a $63 \times$ objective.

Collagen Binding Assay. Briefly, $200 \mu \mathrm{L}$ of the collagen solution (Murine collagen type I/III (Bio-Rad) reconstituted in $0.25 \%$ acetic acid at concentration of $2.0 \mathrm{mg} / \mathrm{mL}$ ) was added to a 96 -well plate and incubated overnight at $4{ }^{\circ} \mathrm{C}$. Prior to the collagen binding study, the plate was blocked with $2 \%$ BSA and washed with PBS. Platelets were stained with WGA Alexa Fluor 594 for $30 \mathrm{~min}$, washed with PBS, and added to collagen-coated or non-collagen-coated plates $\left(\sim 1 \times 10^{7}\right.$ cells $/$ well) in triplicate. After $30 \mathrm{~s}$ of incubation, plates were washed. Retained platelets were dissolved with $100 \mu \mathrm{L}$ of DMSO for fluorescence quantification using a TeCan Infinite M200 reader. For confocal imaging, the collagen solution was added to the confocal well and incubated overnight at $4{ }^{\circ} \mathrm{C}\left(\sim 1 \times 10^{8}\right.$ cells/well). Wells were blocked with $2 \%$ BSA, and WGA Alexa Fluor 594-labeled platelets were incubated with collagen for 2 min, washed with PBS, and analyzed by confocal microscopy using a confocal microscope (Zeiss) in sequential scanning mode using a $63 \times$ objective.

Aggregation Assay. Aggregation of platelets was assessed using confocal imaging. Platelets were labeled with WGA Alexa Fluor 594, loaded to the confocal well, and incubated with 0.5 $\mathrm{U} / \mathrm{mL}$ of thrombin for $30 \mathrm{~min}$. Confocal microscopy was performed on a confocal microscope (Zeiss) in sequential scanning mode using a $63 \times$ objective.

Drug Loading and Release. To prepare cyclophosphamide-loaded platelets, $100 \mu \mathrm{g}$ of purified platelets and $100 \mu \mathrm{g}$ of cyclophosphamide were gently mixed in $1 \mathrm{~mL}$ of PBS and incubated for $2 \mathrm{~h}$ at $37^{\circ} \mathrm{C}$. 44,45 Platelets were then washed with PBS by centrifugation at $12000 \mathrm{rpm}$. For electroporation shock method, $100 \mu \mathrm{g}$ of purified platelets and $100 \mu \mathrm{g}$ of cyclophosphamide were gently mixed in $1 \mathrm{~mL}$ of electroporation buffer (1.15 mM potassium phosphate $\mathrm{pH} 7.2,25$ $\mathrm{mM}$ potassium chloride, $21 \%$ Optiprep) at room temperature. Samples were electroporated at $300 \mathrm{~V}$ and $150 \mu \mathrm{F}$ in $0.4 \mathrm{~cm}$ electroporation cuvettes using a MicroPulser Electro-porator (Bio-Rad). Electroporation cuvettes containing samples were then incubated for $30 \mathrm{~min}$ for the membrane recovery. Platelets were washed with PBS by centrifugation at 12000 rpm. ${ }^{46-48}$ The release of cyclophosphamide from platelets $(100 \mu \mathrm{g} / \mathrm{mL})$ was analyzed in PBS $(\mathrm{pH} \mathrm{7.2)}$ at different time points at $37{ }^{\circ} \mathrm{C}$. The amount of cyclophosphamide released was quantified by using a UV-vis spectrophotometer at 205 nm. 49,50

Circulation. PD-1-expressing platelets and free platelets produced from L8057 cells were labeled by NHS-Cy5.5. Labeled platelets $\left(\sim 2 \times 10^{8}\right.$ cells $)$ were washed with PBS and injected intravenously via tail-vein in C57BL/6 mice in $200 \mu \mathrm{L}$ of final volume. Peripheral blood was collected at different time points after platelet injection, and fluorescence of the serum was measured.

Biodistribution. Free platelets and PD-1-expressing platelets produced from L8057 cells were labeled by NHSCy5.5 in PBS. Following incubation overnight, Cy5.5-labeled platelets $\left(\sim 2 \times 10^{8}\right.$ cells/mouse $)$ were washed with PBS and infused in melanoma tumor-bearing $\mathrm{C} 57 \mathrm{BL} / 6$ mice. The control group was injected with PBS. After $24 \mathrm{~h}$, mice were euthanized, and tumors and organs were harvested. Fluorescence imaging and average radio intensities were recorded using a Xenogen IVIS spectrum imaging system.

In Vivo Antitumor Effects. B16F10 luciferase-tagged B16F10 $\left(1 \times 10^{6}\right.$ cells/mouse $)$ melanoma tumor cells were transplanted into the right flank of $\mathrm{C} 57 \mathrm{BL} / 6 \mathrm{~J}$ mice. When the tumor volumes were around $\sim 130 \mathrm{~mm}^{3}$, the tumors were then resected, leaving about $15 \mathrm{~mm}^{3}(\sim 10 \%)$ tumor to mimic the residual tumors in the surgical bed. Briefly, animals were anesthetized in an induction chamber using isoflurane (up to $5 \%$ for induction; $1-3 \%$ for maintenance), and anesthesia was maintained via a nose cone. The tumor area was clipped and aseptically prepped. Approximately $90 \%$ of the tumor was removed using sterile instruments. The wound was closed using an Autoclip wound closing system. The mice were randomly divided into groups $(n=8)$. Mice were intravenously injected with PBS, free platelets $\left(\sim 2 \times 10^{8}\right.$ cells/mouse $)$, PD-1 platelets $\left(\sim 2 \times 10^{8}\right.$ cells/mouse $)$, cyclophosphamide $(20 \mathrm{mg} /$ $\mathrm{kg})$, cyclophosphamide-loaded free platelets $\left(\sim 2 \times 10^{8}\right.$ cells/ mouse), or cyclophosphamide-loaded PD-1-expressing platelets $\left(\sim 2 \times 10^{8}\right.$ cells/mouse $)$. Immediately after treatment, tumor resection was carried out within $10 \mathrm{~min}$, one mouse by one mouse. The tumor burden was monitored via tumor bioluminescence. Images of the mice bearing tumor were taken using an IVIS Lumina imaging system (PerkinElmer). Tumor size was measured with a digital caliper. The tumor volume $\left(\mathrm{mm}^{3}\right)$ was calculated as (long diameter $\times$ short diameter $\left.{ }^{2}\right) / 2$. Once the mice exhibit signs of impaired health or when the volume of the tumor exceeded $1.5 \mathrm{~cm}^{3}$, the mice were euthanized with $\mathrm{CO}_{2}$.

Tissue Immunofluorescent Assay. Tumors were harvested from the mice and snap frozen in optimal cutting medium (O.C.T.). Ten micrometer sections were cut using a cryotome and mounted on slides. Frozen tumor sections were incubated in PBS for $15 \mathrm{~min}$ to remove the embedding medium. Specimens were blocked with the buffer containing $3 \%$ BSA, incubated with CD4 and CD8 antibodies (1:50 in 3\% BSA) overnight, washed with PBS, stained with TRITC secondary antibody (KPL) diluted in $1.5 \%$ BSA at room temperature, and kept in the dark for $1 \mathrm{~h}$. The nucleus was stained with DAPI and washed with PBS. Confocal microscopy was performed on a FLUO-VIEW laser scanning confocal microscope (Zeiss) in sequential scanning mode using a $40 \times$ objective.

Statistical Analysis. All results are expressed as the mean $\pm \mathrm{SD}$ or the mean \pm SEM as indicated. Biological replicates were used in all experiments unless otherwise stated. One-way or two-way analysis of variance (ANOVA) and Tukey posthoc 
tests were used when more than two groups were compared (multiple comparisons). Survival benefit was determined using a log-rank test. All statistical analyses were performed using the IBM SPSS statistics 19. The threshold for statistical significance was $P<0.05$.

\section{ASSOCIATED CONTENT}

\section{Supporting Information}

The Supporting Information is available free of charge on the ACS Publications website at DOI: 10.1021/acs.nanolett.8b02321.

In vitro process of platelet releasing from L8057 cells, establishment of L8057 cell line stably expressing EGFPPD-1, activity of platelets released from L8057 cells, in vitro binding and uptake of platelets by tumor cells, tumor size and body weight of mice, histological images for $H \& E$ staining, in vitro loading and release of cyclophosphamide by PD-1-expressing platelets, and the bioluminescence imaging of B16F10 tumor growth in mice after partial tumor resection and receiving the treatments (PDF)

\section{AUTHOR INFORMATION}

\section{Corresponding Authors}

*E-mail: peng.huang@szu.edu.cn.

*E-mail: guzhen@ucla.edu.

\section{ORCID}

Zhaowei Chen: 0000-0001-9007-5513

Junjie Yan: 0000-0001-8016-2277

Peng Huang: 0000-0003-3651-7813

Zhen Gu: 0000-0003-2947-4456

\section{Author Contributions}

X.Z. and J.W. contributed equally to this work. X.Z., P.H.. and Z.G. designed the study. X.Z., Z.C., Q.H., C.W., J.W., and J.Y. performed the experiments. X.Z. interpreted the data. The manuscript was written through contributions of all authors. All authors have given approval to the final version of the manuscript.

\section{Notes}

The authors declare no competing financial interest.

\section{ACKNOWLEDGMENTS}

This work was supported by grants from the Alfred P. Sloan Foundation (Sloan Research Fellowship), and a pilot grant from the University of North Carolina (UNC) Cancer Center, the National Natural Science Foundation of China (31771036, 51573096, 51703132, 51728301), the Basic Research Program of Shenzhen (JCYJ20170412111100742, JCYJ20160422091238319), Fok Ying-Tong Education Foundation for Young Teachers in the Higher Education Institutions of China (161032), and China Podtdoctoral Science Foundation (2017M612742). We acknowledge Professor Alan Cantor at Boston Children's Hospital and Dana-Farber Cancer Institute for providing the mouse megakaryocyte cell line L8057 cells, and Professor Leaf Huang at University of North Carolina at Chapel Hill for providing B16F10-luc cells.

\section{REFERENCES}

(1) Stephan, S. B.; Taber, A. M.; Jileaeva, I.; Pegues, E. P.; Sentman, C. L.; Stephan, M. T. Nat. Biotechnol. 2015, 33, 97-101.
(2) Tohme, S.; Simmons, R. L.; Tsung, A. Cancer Res. 2017, 77, $1548-1552$.

(3) Uramoto, H.; Tanaka, F. Transl. Lung Cancer Res. 2014, 3 (4), 242-249.

(4) Kanwar, S. S.; Poolla, A.; Majumdar, A. P. World J. Gastrointest. Pathophysiol. 2012, 3, 1-9.

(5) Disis, M. L.; Stanton, S. E. Clin. Cancer Res. 2013, 19, 63986403.

(6) Schumacher, T. N.; Schreiber, R. D. Science 2015, 348, 69-74.

(7) Balachandran, V. P.; Luksza, M.; Zhao, J. N.; Makarov, V.; Moral, J. A.; Remark, R.; Herbst, B.; Askan, G.; Bhanot, U.; Senbabaoglu, Y.; Wells, D. K.; et al. Nature 2017, 551 (7681), 512516.

(8) Ott, P. A.; Hu, Z.; Keskin, D. B.; Shukla, S. A.; Sun, J.; Bozym, D. J.; Zhang, W.; Luoma, A.; Giobbie-Hurder, A.; Peter, L.; et al. Nature 2017, 547, 217-221.

(9) Gubin, M. M.; Zhang, X.; Schuster, H.; Caron, E.; Ward, J. P.; Noguchi, T.; Ivanova, Y.; Hundal, J.; Arthur, C. D.; Krebber, W. J.; et al. Nature 2014, 515 (7528), 577-81.

(10) Sharma, P.; Allison, J. P. Cell 2015, 161, 205-214.

(11) Boussiotis, V. A. N. Engl. J. Med. 2016, 375, 1767-1778.

(12) Zou, W.; Wolchok, J. D.; Chen, L. Sci. Transl. Med. 2016, 8, 328 rv4.

(13) Sharma, P.; Allison, J. P. Science 2015, 348, 56-61.

(14) Hoos, A. Nat. Rev. Drug Discovery 2016, 15, 235-247.

(15) Chen, Q.; Xu, L.; Liang, C.; Wang, C.; Peng, R.; Liu, Z. Nat. Commun. 2016, 7, 13193.

(16) Sharma, P.; Hu-Lieskovan, S.; Wargo, J. A.; Ribas, A. Cell 2017, $168,707-723$.

(17) von Boehmer, H. Nat. Immunol. 2005, 6, 338-44.

(18) Zou, W. Nat. Rev. Immunol. 2006, 6, 295-307.

(19) Grossman, W. J.; Verbsky, J. W.; Barchet, W.; Colonna, M.; Atkinson, J. P.; Ley, T. J. Immunity 2004, 21, 589-601.

(20) Maj, T.; Wang, W.; Crespo, J.; Zhang, H.; Wei, S.; Zhao, L.; Vatan, L.; Shao, I.; Szeliga, W.; Lyssiotis, C.; Liu, J. R.; Kryczek, I.; Zou, W. Nat. Immunol. 2017, 18, 1332-1341.

(21) Golebiewska, E. M.; Poole, A. W. Blood Rev. 2015, 29, $153-$ 162.

(22) Nurden, A. T.; Nurden, P.; Sanchez, M.; Andia, I.; Anitua, E. Front Biosci. 2008, 13, 3532-3548.

(23) Wang, C.; Sun, W.; Ye, Y.; Hu, Q.; Bomba, H. N.; Gu, Z. Nat. Biomed. Eng. 2017, 1, 0011.

(24) Hu, C. M.; Fang, R. H.; Wang, K. C.; Luk, B. T.; Thamphiwatana, S.; Dehaini, D.; Nguyen, P.; Angsantikul, P.; Wen, C. H.; Kroll, A. V.; et al. Nature 2015, 526, 118-121.

(25) Anselmo, A. C.; Modery-Pawlowski, C. L.; Menegatti, S.; Kumar, S.; Vogus, D. R.; Tian, L. L.; Chen, M.; Squires, T. M.; Sen Gupta, A.; Mitragotri, S. ACS Nano 2014, 8, 11243-11253.

(26) Hu, Q.; Sun, W.; Qian, C.; Wang, C.; Bomba, H. N.; Gu, Z. Adv. Mater. 2015, 27, 7043-7050.

(27) Li, S.; Jiang, Q.; Liu, S.; Zhang, Y.; Tian, Y.; Song, C.; Wang, J.; Zou, Y.; Anderson, G. J.; Han, J. Y.; Chang, Y.; Liu, Y.; Zhang, C.; Chen, L.; Zhou, G.; Nie, G.; Yan, H.; Ding, B.; Zhao, Y. Nat. Biotechnol. 2018, 36, 258-264.

(28) Stroncek, D. F.; Rebulla, P. Lancet 2007, 370, 427-438.

(29) Moreau, T.; Evans, A. L.; Vasquez, L.; Tijssen, M. R.; Yan, Y.; Trotter, M. W.; Howard, D.; Colzani, M.; Arumugam, M.; Wu, W. H.; et al. Nat. Commun. 2016, 7, 11208.

(30) Li, J.; Sharkey, C. C.; Wun, B.; Liesveld, J. L.; King, M. R. J. Controlled Release 2016, 228, 38-47.

(31) Lefrancais, E.; Ortiz-Munoz, G.; Caudrillier, A.; Mallavia, B.; Liu, F.; Sayah, D. M.; Thornton, E. E.; Headley, M. B.; David, T.; Coughlin, S. R.; et al. Nature 2017, 544 (7648), 105-109.

(32) Zhang, X.; Wang, C.; Wang, J.; Hu, Q.; Langworthy, B.; Ye, Y.; Sun, W.; Lin, J.; Wang, T.; Fine, J.; Cheng, H.; Dotti, G.; Huang, P.; Gu, Z. Adv. Mater. 2018, 30, 1707112.

(33) Machlus, K. R.; Italiano, J. E., Jr. J. Cell Biol. 2013, 201, 785796. 
(34) Ruggeri, Z. M.; Mendolicchio, G. L. Circ. Res. 2007, 100, $1673-1685$.

(35) Semple, J. W.; Italiano, J. E., Jr.; Freedman, J. Nat. Rev. Immunol. 2011, 11, 264-274.

(36) Siljander, P. R. Thromb. Res. 2011, 127, S30-S33.

(37) Mause, S. F.; von Hundelshausen, P.; Zernecke, A.; Koenen, R. R.; Weber, C. Arterioscler., Thromb., Vasc. Biol. 2005, 25, 1512-1518.

(38) Rollinghoff, M.; Starzinski-Powitz, A.; Pfizenmaier, K.; Wagner, H. J. Exp. Med. 1977, 145, 455-459.

(39) Yoshida, S.; Nomoto, K.; Himeno, K.; Takeya, K. Clin. Exp. Immunol. 1979, 38 (2), 211-217.

(40) Berd, D.; Mastrangelo, M. J. Cancer Res. 1988, 48 (6), 16711675.

(41) Chen, Q.; Wang, C.; Chen, G.; Hu, Q.; Gu, Z. Adv. Healthcare Mater. 2018, 1800424.

(42) Wang, C.; Wang, J.; Zhang, X.; Yu, S.; Wen, D.; Hu, Q.; Ye, Y.; Bomba, H.; Hu, X.; Liu, Z.; Dotti, G.; Gu, Z. Sci. Transl. Med. 2018, 10, 429.

(43) Zhang, X.; Dong, Y.; Zeng, X.; Liang, X.; Li, X.; Tao, W.; Chen, H.; Jiang, Y.; Mei, L.; Feng, S. S. Biomaterials 2014, 35 (6), 1932-43. (44) Jang, S. C.; Kim, O. Y.; Yoon, C. M.; Choi, D. S.; Roh, T. Y.; Park, J.; Nilsson, J.; Lotvall, J.; Kim, Y. K.; Gho, Y. S. ACS Nano 2013, 7, 7698-7710.

(45) Wen, D.; Peng, Y.; Liu, D.; Weizmann, Y.; Mahato, R. I. J. Controlled Release 2016, 238, 166-175.

(46) Alvarez-Erviti, L.; Seow, Y.; Yin, H.; Betts, C.; Lakhal, S.; Wood, M. J. Nat. Biotechnol. 2011, 29, 341-345.

(47) El-Andaloussi, S.; Lee, Y.; Lakhal-Littleton, S.; Li, J.; Seow, Y.; Gardiner, C.; Alvarez-Erviti, L.; Sargent, I. L.; Wood, M. J. Nat. Protoc. 2012, 7, 2112-2126.

(48) Tian, Y.; Li, S.; Song, J.; Ji, T.; Zhu, M.; Anderson, G. J.; Wei, J.; Nie, G. Biomaterials 2014, 35, 2383-2390.

(49) Gulfam, M.; Kim, J. E.; Lee, J. M.; Ku, B.; Chung, B. H.; Chung, B. G. Langmuir 2012, 28, 8216-8223.

(50) Kensler, T. T.; Behme, R. J.; Brooke, D. J. Pharm. Sci. 1979, 68, 172-174. 